Яковлева Т. А., Ким Е. В.

T. A. Yakovleva, E. V. Kim

ФАКТОРЫ РАЗВИТИЯ И СДЕРЖИВАНИЯ ДЕЯТЕЛЬНОСТИ В СТРОИТЕЛЬСТВЕ

\title{
FACTORS OF DEVELOPMENT AND CONTAINMENT OF CONSTRUCTION ACTIVITIES
}

Яковлева Татьяна Анатольевна - кандидат экономических наук, доцент, заведующая кафедрой экономики, финансов и бухгалтерского учёта Комсомольского-на-Амуре государственного университета (Россия, Комсомольск-на-Амуре); 681013, Хабаровский край, г. Комсомольск-на-Амуре, пр. Ленина, 27. E-mail: efbu@knastu.ru.

Ms. Tatiana A. Yakovleva - PhD in Economics, associate Professor, head of the Department of Economics, Finance and accounting, Komsomolsk-on-Amur State University (Russia, Komsomolsk-on-Amur); 681013, Khabarovsk territory, Komsomolsk-on-Amur, 27 Lenin str. E-mail: efbu@knastu.ru.

Ким Евгений Владимирович - студент магистратуры направления 38.04.01 «Экономика» Комсомольского-на-Амуре государственного университета (Россия, Комсомольск-на-Амуре); 681013, Хабаровский край, г. Комсомольск-на-Амуре, пр. Ленина, 27. E-mail: ev_h222os@mail.ru.

Mr. Evgeny V. Kim - master's degree student major in Economics, Komsomolsk-on-Amur State University (Russia, Komsomolsk-on-Amur); 681013, Khabarovsk territory, Komsomolsk-on-Amur, 27 Lenin str. E-mail: ev_h222os@mail.ru.

Аннотация. В статье изучена динамика объёма выполненных работ и количества организаций по виду экономической деятельности «строительство». Далее проанализированы факторы, способствующие приросту основных показателей, и факторы, ограничивающие производственную деятельность строительных организаций в России. В заключении приведена динамика индекса предпринимательской уверенности в строительстве.

Summary. The article studies the dynamics of the volume of work performed and the number of organizations major in construction. The factors contributing to the growth of key indicators and factors limiting the production activities of construction companies in Russia are analyzed. In conclusion, the dynamics of the index of business confidence in construction is presented.

Ключевые слова: строительные работы, факторы роста, индекс предпринимательской уверенности.

Key words: construction work, growth factors, business confidence index.

УДК 69.003

В современной экономике строительство представляет собой отдельный самостоятельный вид деятельности, направленный на ввод в действие новых, а также ремонт и техническое перевооружение действующих объектов производственного и непроизводственного назначения.

В соответствии с «Общероссийским классификатором видов экономической деятельности» (коды 2018) к строительным работам относят:

- строительство новых объектов;

- реконструкцию, капитальный и текущий ремонт, дополнительные работы;

- монтаж готовых зданий или сооружений на строительном участке, включая строительство временных сооружений [1].

Определяющая роль строительства как отрасли национального хозяйства заключается в создании условий для устойчивого развития экономики России. Обобщающим показателем функционирования строительства, позволяющего оценить эту роль, является объём выполненных работ. Согласно данным Федеральной службы государственной статистики [3], объём работ, выполненных по виду экономической деятельности «строительство», в целом по стране вырос с 503,8 млрд 
рублей в 2001 году до 7204,2 млрд рублей в 2017-м (см. рис. 1). Несложно рассчитать, что прирост объёма строительных работ за названный период времени составил более 1000 \%, что характеризует этот вид деятельности как один из наиболее динамично развивающихся.

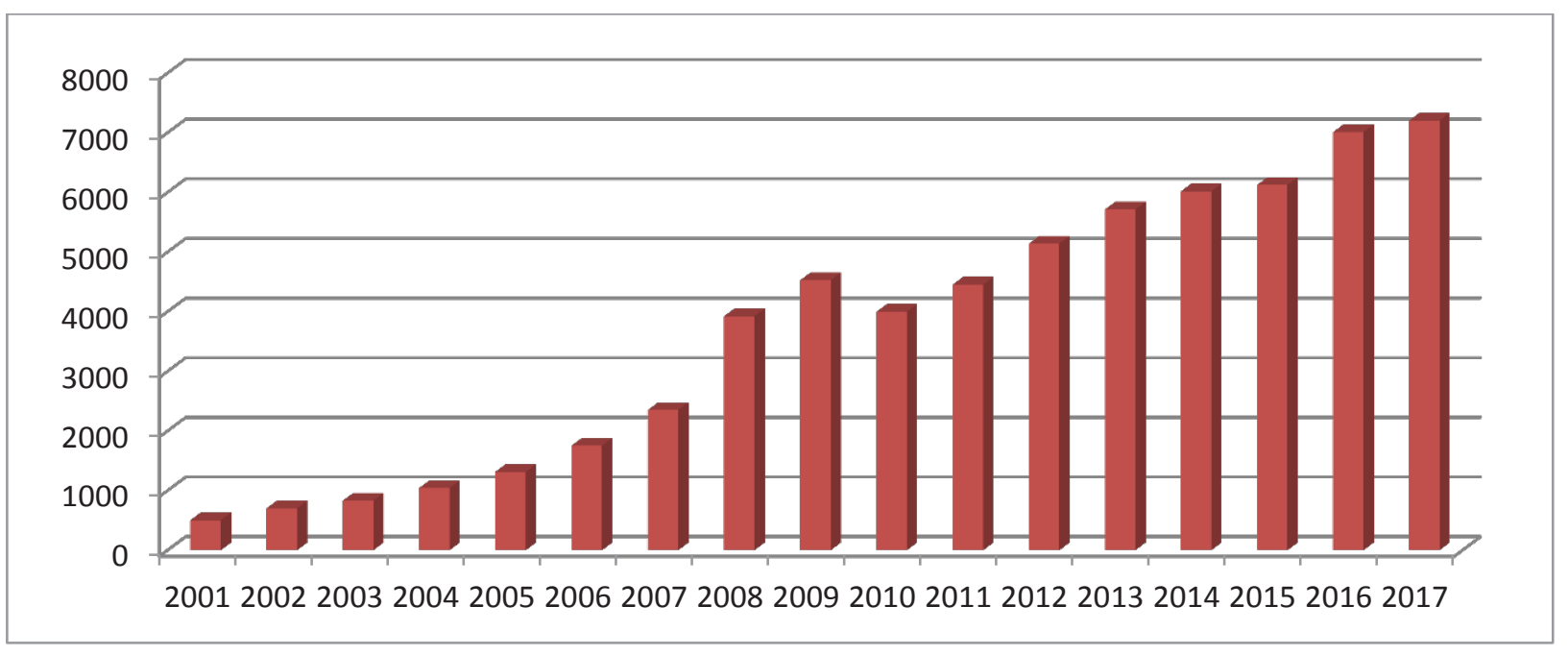

Рис. 1. Динамика объёма работ по виду экономической деятельности «строительство» в Российской Федерации, млрд руб. (создан авторами)

Общеизвестно, что обеспечить прирост объёма работ можно двумя принципиально различными способами:

1) экстенсивным, достигаемым за счёт увеличения количества организаций и численности работников, занятых строительными работами;

2) интенсивным, который возможен за счёт роста производительности труда в строительстве.

Рассмотрим динамику количества строительных организаций (см. рис. 2) и изменение производительности труда в отрасли за аналогичный период.

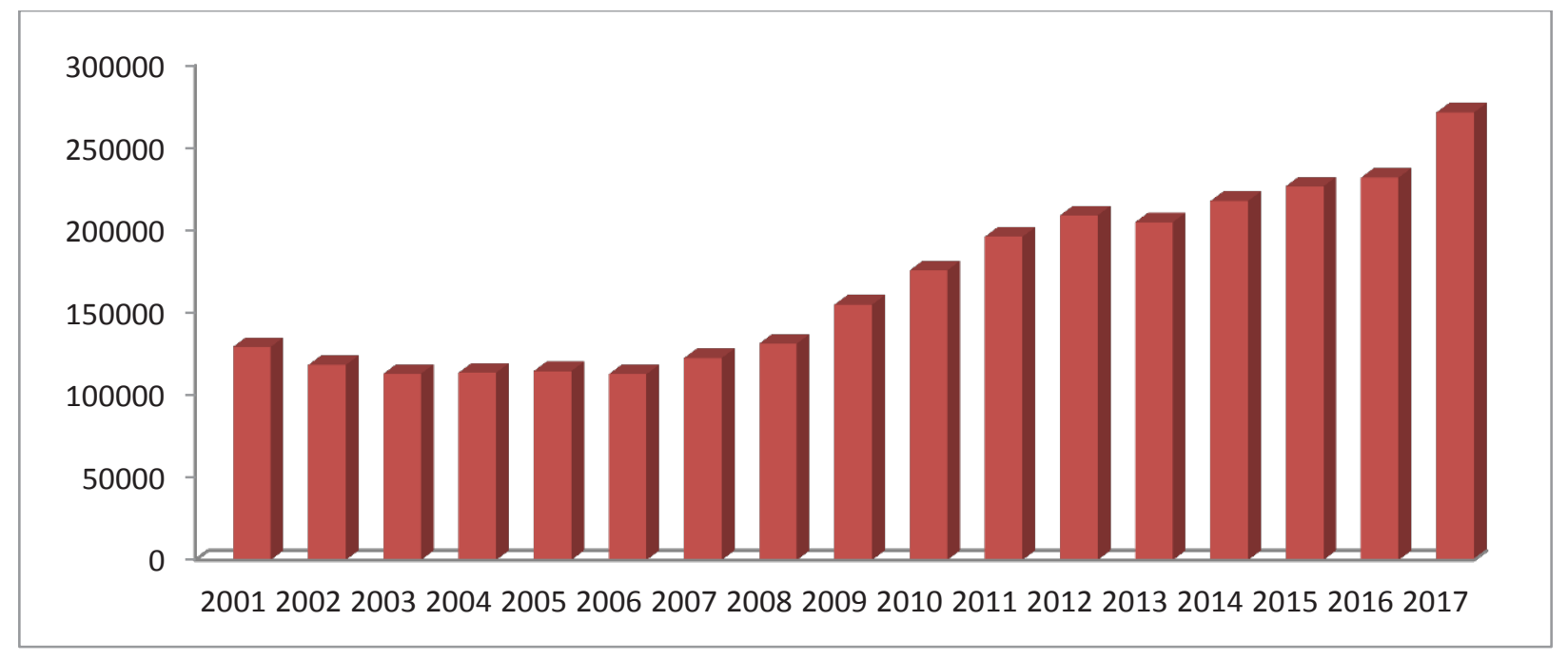

Рис. 2. Динамика количества строительных организаций в РФ (создан авторами)

Количество действующих строительных организаций в российской экономике увеличилось с 2001 по 2017 гг. более чем в 2 раза, достигнув в 2017 году 271 604. Иными словами, прирост ко- 
Яковлева Т. А., Ким Е. В.

ФАКТОРЫ РАЗВИТИЯ И СДЕРЖИВАНИЯ ДЕЯТЕЛЬНОСТИ В СТРОИТЕЛЬСТВЕ

личества строительных организаций составил чуть более $100 \%$, что в 10 раз меньше прироста объёма выполненных работ в строительстве. Следовательно, имеет место влияние интенсивных факторов роста, в том числе производительности труда.

Динамика производительности труда в строительстве в расчёте на единицу затрат рабочего времени представлена в табл. 1.

Таблица 1

Динамика производительности труда в строительстве [2]

\begin{tabular}{|l|c|c|c|c|c|c|}
\hline Годы (периоды) & 2004 & 2006 & 2008 & 2010 & 2012 & 2014 \\
\hline $\begin{array}{l}\text { Производительность } \\
\text { труда, р./час }\end{array}$ & 93,14 & 109,46 & 163,58 & 202,46 & 385,18 & 375,58 \\
\hline
\end{tabular}

Из данных табл. 1 видно, что за десятилетний период уровень производительности труда в строительстве возрос в 4 раза. Графическая иллюстрация динамики производительности труда представлена на рис. 3 .

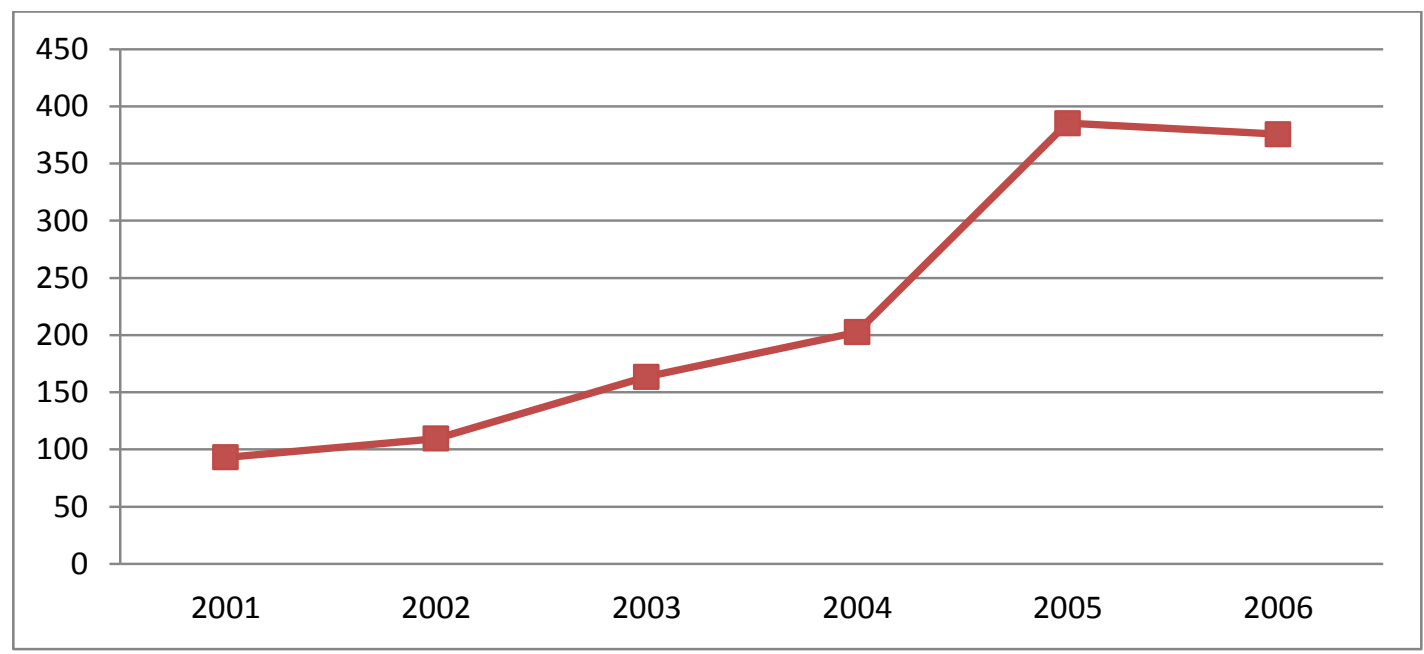

Рис. 3. Динамика производительности труда в строительстве (создан авторами)

Таким образом, можно сделать вывод о том, что увеличение объёма работ по виду экономической деятельности более чем в 100 раз является результатом действия как экстенсивных, так и интенсивных факторов.

Несмотря на положительную динамику основных показателей деятельности строительной отрасли существует ряд факторов, препятствующих её дальнейшему развитию. К основным факторам, ограничивающим производственную деятельность, по мнению руководителей строительных организаций, можно отнести:

- высокий уровень налогов;

- высокую стоимость материалов, конструкций, изделий;

- недостаток заказов на осуществление работ;

- неплатёжеспособность заказчиков;

- высокий процент коммерческого кредита;

- другое.

По материалам выборочного исследования составлен рейтинг названных факторов, который в течение года претерпел некоторые изменения. В частности, увеличилось количество респондентов, ощущающих отрицательное влияние «недостатка заказов на выполнение работ» и «погодных условий». В то же время уменьшилась доля участников опроса, считающих, что производственную деятельность строительных организаций ограничивают «высокий уровень нало- 
гов», «высокая стоимость материалов, конструкций, изделий» и «неплатёжеспособность заказчиков» (см. рис. 4).

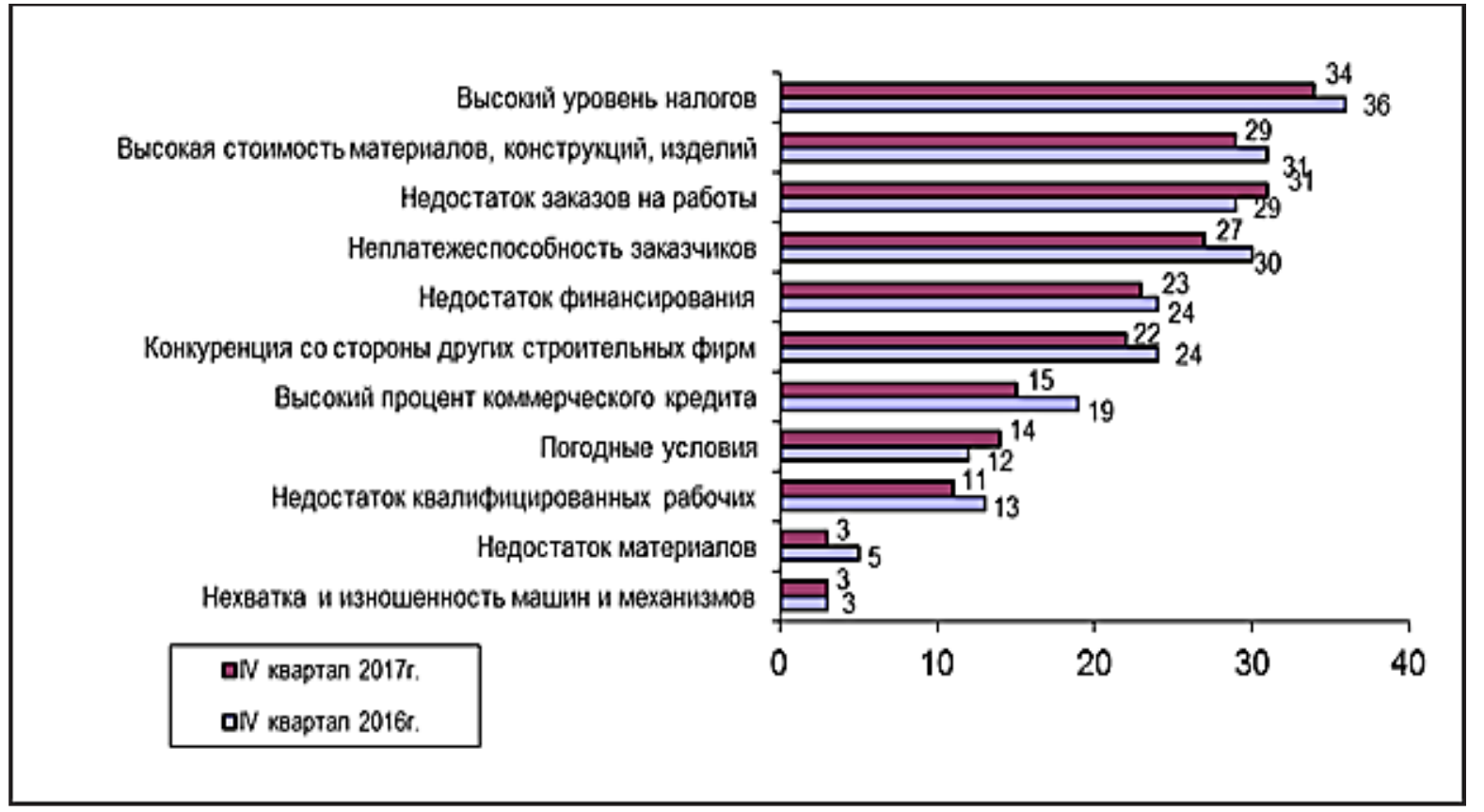

Рис. 4. Факторы, ограничивающие производственную деятельность строительных организаций

Действие ограничивающих факторов приводит к снижению инвестиционной активности, что в свою очередь может привести к снижению темпов роста в строительстве. Результаты исследований деловой активности строительных организаций в IV квартале 2017 года свидетельствуют о нестабильной экономической ситуации в строительном секторе. Так, среди руководителей строительных организаций индекс предпринимательской уверенности в IV квартале 2017 года составил -21\%, что на 8 процентных пунктов ниже, чем в IV квартале 2016 года.

При этом в 13 субъектах Российской Федерации наблюдалось повышение деловой активности в IV квартале 2017-го. Результаты проведённого исследования свидетельствуют, что в 24 из 82 субъектов Российской Федерации, участвующих в исследовании, индекс предпринимательской уверенности выше, чем в среднем по России. Самое низкое значение индекса предпринимательской уверенности (-60\%) зафиксировано в Хабаровском крае, что является крайне тревожным симптомом в условиях формирования здесь двух территорий опережающего развития - ТОР «Хабаровск-2» и ТОР «Комсомольск».

\section{ЛИТЕРАТУРА}

1. Коды ОКВЭД 2018 с расшифровкой (ОКВЭД 2). Общероссийский классификатор видов экономической деятельности [Электронный ресурс]. - Режим доступа: http://новыеформы.рф (дата обращения 20.03.2018). 2. Лядова, Е. В. Анализ динамики производительности труда в России: макроэкономический аспект Е. В. Лядова // Вестник Нижегородского университета имени Н. И. Лобачевского. Социальные науки, 2017. № 1(45). - C. 46-53. URL: https://cyberleninka.ru (дата обращения: 20.03.2018).

3. Федеральная служба государственной статистики России [Электронный ресурс]. - Режим доступа: http://www.gks.ru (дата обращения: 20.03.2018). 